\title{
THE IMPLEMENTATION AND EVALUATION OF A BEHAVIOUR-BASED SAFETY INTERVENTION AT AN IRON ORE MINE
}

\author{
GP Möller and S Rothmann
}

WorkWell: Research Unit for People, Policy and Performance, North-West University, Potchefstroom

\begin{abstract}
It is estimated that workers worldwide suffer 250 million accidents each year, with 330000 fatalities. This is despite the implementation of traditional safety interventions like safety engineering. Little emphasis has thus far been placed on behavioural interventions to improve safety culture and performance in the workplace. The aim of this study was to determine to what extent the safety culture and safety performance in an iron ore mine were affected by the implementation of a behaviour-based safety intervention. A longitudinal design was used. The sample consisted of 562 employees of an iron ore mine. The results showed that the implementation of the safety intervention brought about an improvement in the safety culture at the mine, and positively impacted on the number of lost-time injuries.
\end{abstract}

JEL J28, M10

\section{1 \\ Introduction}

It is estimated that workers worldwide suffer 250 million accidents every year, with 330000 fatalities and 160 million cases of occupational disease. An even higher number of threats to employees' physical and mental well-being cause further suffering. The consequent economic losses are equivalent to four percent of the world's gross national product (International Labour Organisation, 1999). In terms of shattered families and communities, the damage is certainly incalculable. In South Africa the situation is not at all any better. During the period 1999-2001, an average annual number of 426 fatalities was recorded (Department of Labour, 2002). These fatalities occurred despite safety interventions which were implemented, including safety design, ergonomics, management audits, poster campaigns, near-miss reporting and root cause analysis.

The mine where the current study was conducted is the third-largest iron ore mine in the world. The mine produces 26 million tons of beneficiated iron ore per annum, of which approximately 20 million tons are exported to 16 countries abroad, while the balance is delivered to local steel works. The mine employs 3346 permanent employees, of which 16,4 per cent are illiterate. As is the case in most South African and overseas companies, the mine also experienced a number of safety problems, namely: a) An unacceptably high injury rate of 5.53 lost time injuries per 1 million hours worked. The benchmark rate in similar leading companies is fewer than two injuries per million hours worked (Toellner, 2001). The injury rate reached a plateau in spite of the implementation of various other interventions (except behaviourbased safety) that are available "on the market". b) An average number of one fatality per annum, which is unacceptable, considering that the target is zero. c) A total of 85 per cent of all injuries at the mine being caused by risky behaviour and not by other causes, like unsafe conditions or lack of training. d) The safety culture on the shop floor could improve. Employees were not empowered to make a difference in safety, and only supervisors and managers were in a position to contribute to safety. 
The development of a proper safety management system requires continual attention to three domains, namely the environment, the person and behaviour (Smith, Karsh, Carayon \& Conway, 2003). The environment refers to equipment, tools, machines, task characteristics, the work environment and the organisational structure. A number of safety interventions can be applied to continually improve safety conditions in the environment, like engineering changes and ergonomics (Sanders \& McCormick, 1993). Person factors include intelligence, knowledge, skills, aptitudes, perceptual-motor abilities, current health status, personality and attitudes (Smith et al., 2003). From a safety point of view it is important to pay thorough attention to this domain. The third domain that requires continuous attention is behaviour. Behaviour refers to specific observable actions by an individual. There are three types of behaviour that concern safety, namely conscious, habitual and unintentional behaviour (Smith et al., 2003). Conscious behaviour refers to actions where employees consciously comply with or violate safety procedures, like when they are taking short-cuts to achieve certain goals. Habitual behaviour refers to actions that are being performed automatically, like fastening a safety belt before driving an automobile. Unintentional behaviour in safety refers to actions performed by employees who are unconsciously incompetent, or a state in which the employee did not know that there was a better way to perform a specific task. In order to continually improve safety performance, much emphasis must be placed on these three types of behaviour.

Historically many organisations have focused on improving safety by addressing "the work environment" and "the person". In South Africa, in particular, very little emphasis has thus far been placed on behavioural interventions to improve safety culture and safety performance in the workplace. Providing hazard-free facilities and better tools and equipment have worked well to improve safety performance but many organisations have reached a plateau, continuing to rely solely on those approaches that will bring only marginal gains (Findley, 2003). Traditional approaches to safety management are based on efforts to improve the engineering and the work environment, and/or authoritarian management models that rely on hierarchical structures, the formalising of rules and procedures and policing employees to enforce the rules (Smith et al., 2003). By also focusing on safety-related behaviours before accidents happen, companies can make step-change improvements in their safety performance (Findley, 2003).

Although there is no single cause of an incident or injury, behaviour and safety are strongly connected (Geller, 1996). Over the past three decades, behaviour-based safety for performance improvement was developed integrating behavioural science, quality, and organisation development principles with safety management in order to reduce occupational injuries (Krause, 2001). A behaviour-based safety intervention could be applied to address the behaviour aspect of safety (Geller, 1996; Krause, 1995).

The aim of this study was to determine to what extent the safety culture and safety performance in an iron ore mine were affected by the implementation of a behaviour-based safety intervention.

\section{2}

\section{Behaviour-based safety}

A behaviour-based safety intervention includes the application of principles and methods derived from the field of applied behaviour analysis to industrial safety. These principles include rewarding feedback and positive reinforcement to increase appropriate behaviour and corrective feedback to decrease improper behaviour (Blair, 1999). The behaviour-based approach to safety focuses strictly on observable, measurable actions that are critical to safety at a particular site facility (Krause, 1995). This is a task-oriented view of behaviour, and it treats safety-related behaviour as critical work-related skills to be identified and inventoried.

The behaviour-based process firstly involves defining the problem (risky behaviour) and then designing and implementing an intervention process to decrease behaviour causing the problem and/or to increase behaviour that can alleviate the problem (Smith et al., 2003). 
According to Geller et al. (1998), behaviourbased safety consists of four steps, namely a) define the target behaviour to be increased or decreased; b) observe the target behaviour through formal observations and record the results in a data management system; c) intervene to change the target behaviour in desired directions, and d) test the impact of the intervention procedure by continuing to observe and record the target behaviour.

Krause (2001) and Geller (1998) set essentials for a successful behaviour-based programme. It involves significant workforce participation. Without widespread involvement, the ownership of and commitment to the process will be lacking and the process will probably fail. Furthermore, it targets specific unsafe behaviour. The unsafe behaviour identified in the process is written on a checklist in a system where employees observe each other. Behaviour-based safety is based on observational data collection, on the basis of "what gets measured gets done". Safe and unsafe behaviour are fed into a database system, so that behaviour can be monitored on a regular basis. The higher the number of observations, the more reliable the data. The very act of observing and measuring people's safety behaviour alters the behaviour of those being observed (Krause, 2001). The observation scores are turned into some form of metric: usually the percentage of behaviours performed safely and unsafely. By examining these trends it becomes clear what corrective actions should focus on.

The process involves a systematic improvement intervention. Interventions are not developed in a haphazard way, but specifically target the elimination of unsafe behaviour. After implementation, the effect of such an intervention will again be tested through observations. There are two very important factors regarding the impacts of interventions on behaviour, namely the role that consequences play in behaviour, and the fact that safety is a continuous struggle against human nature. Human nature typically encourages risk behaviour (Geller, 1996). Human nature always prefers comfort, convenience and inefficiency. For example, wearing earplugs in a noisy environment for almost the entire shift, or a welder wearing a leather apron in a workshop at 40 degrees Celsius, is against human nature. Supervisors should be aware of these aspects, and should consider this when they attempt to change behaviour.

In addition, behaviour is motivated by consequences (Skinner, 1965). If consequences are soon, certain, and sizeable, those will be highly motivational factors that drive behaviour (Geller, 1996). In the workplace strange risk behaviour is often the result of perceived consequences. There are instances where employees were fatally injured at work because they chased production targets and production bonuses (the consequence).

Behaviour-based safety involves regular focused feedback regarding performance (Smith et al., 2003). Feedback is the key ingredient of any type of improvement initiative. Such feedback usually takes three forms: Verbal feedback to people at the time of the observation; graphical feedback on large graphs placed in strategic locations in the workplace; and monthly briefings during safety meetings where observation scores are analysed. Employees use observation techniques such as checklists to periodically observe each other and then give appropriate one-on-one coaching feedback regarding safety-related behaviour. The aim of the feedback is in the first instance to positively reinforce the safe behaviour. Most people tend to respond more to praise and social approval than to any other factor (Geller, 1998). It is crucial to explicitly link the desired safe behaviour to the praise received. Through the observation and feedback process a learning culture is being established (Geller, 1996). The significance of corrective feedback in safety is that it will pave the road to safe habits. It will take the performance of a specific task through the phases of unconscious unsafe behaviour, to conscious unsafe behaviour, to conscious safe behaviour, to unconscious safe behaviour (Geller, 1998).

The crucial question is whether the application of a behaviour-based safety intervention works for safety. Gillmore et al. (2001) reported a 79 per cent reduction in recordable injury rates within seven years following behaviour-based safety implementation. In a nationwide survey in America, 80 per cent of respondents $(N=129)$ 
answered yes to the question: "Do you believe behaviour-based safety is a viable approach for reducing at risk behaviours and activities". Only 3 per cent responded negatively to this question (Geller et al., 1998).

Most of the studies on safety improvement interventions systematically evaluated whether a particular programme worked in a particular situation, but they do not compare one approach with another (see Bird \& Germain, 1996). An exception was the research done by Guastello (1993). His research compared the relative importance of different interventions with one another. He concluded that behaviour-based safety interventions accounted for 59.6 per cent reduction in injuries at seven sites that were investigated, while other interventions together accounted for 40.4 per cent of injury reductions (Guastello, 1993). In this research a behaviour-based intervention was compared to other safety interventions, like ergonomics, engineering changes, government action, management audits, stress management, poster campaigns, personnel selections and near-miss reporting systems. While the goal of such a programme is to identify and increase critical safety-related behaviours, the process can achieve much more than this. This process can be the key to improving organisations' overall safety culture.

Organisations that have a sound safety culture perform better than those that do not (Geller, 1996). Through the implementation of behaviour-based safety an organisation could achieve the desired safety culture. The behaviour of people is driven by culture and not by supervisors or standard operating procedures. Furthermore, a behaviour-based safety process can contribute towards creating the desired culture (Geller, 1996; Gillmore et al., 2001).

According to Blair (1999), every site is unique and customisation of behaviour-based safety is crucial to success. There are reasons why it is necessary to adapt the programme to fit the local circumstances. First, a substantial percentage of employees in South Africa are still illiterate. As participation in the programme requires employees to complete a checklist during the observation process, it is necessary to cater for this issue when developing such a programme. Second, South Africa is also very unionised. Because the behaviour-based safety programme is supposed to be an employee-driven programme, this requires a special relationship with labour unions. Third, employees are exposed to various official languages. This requires training manuals to be translated and training to be presented to employees in at least three different languages. Fourth, cultural differences exist in South Africa. Black employees are often not comfortable with walking up to their peers and observing them. Fifth, because of the high crime rate in South Africa, employees often do not perceive the workplace as being unsafe, despite the high injury and fatality rate. A total number of around 22000 citizens are murdered in South Africa each year, and approximately 88 000 armed robberies take place every year (Gun Control Alliance, 2002). So employees perceive the 426 occupational fatalities in South Africa as insignificant.

All of these issues require special consideration if a behaviour-based safety programme is to be implemented in a developing country like South Africa. It was against this background that the mine decided to implement a behaviour-based safety intervention. The hypothesis is that implementing such a programme will bring a shift in the safety culture at the mine, as well as fewer injuries and equipment damage.

3

Method

\subsection{Research design}

A longitudinal study was carried out to test the effect of a behaviour-based safety intervention (Huysamen, 1996). The first survey was done in December 1999 (just prior to the implementation of the safety behaviour intervention) and the follow-up survey in 2002, to assess any significant changes.

\subsection{Participants}

The mine employs 3346 permanent employees. During the survey 600 employees were randomly selected. This sample represented 20 per cent of the permanent employee population (based 
on the number of employees in 1999). 585 employees responded by completing the survey questionnaire. A total of 23 returned surveys were discarded because the participants had failed to complete 14 or more survey items (10 per cent). A breakdown of the participants by department, position and race is depicted in Table 1.

\section{Table 1}

Breakdown of participants by department, position and race

\begin{tabular}{|l|c|c|}
\hline Department & Frequency & Percentage \\
\hline Plant maintenance & 5 & $10.0 \%$ \\
\hline Plant production & 97 & $17.3 \%$ \\
\hline Mining maintenance & 5 & $9.3 \%$ \\
\hline Mining production & 139 & $24.7 \%$ \\
\hline Engineering service & 40 & $7.1 \%$ \\
\hline Repair shop & 39 & $6.9 \%$ \\
\hline Loading & 32 & $5.7 \%$ \\
\hline $\begin{array}{l}\text { Materials mgmt \& } \\
\text { planning dev }\end{array}$ & 26 & $4.6 \%$ \\
\hline BABI, finance \& Cl & 35 & $6.2 \%$ \\
\hline $\begin{array}{l}\text { Human resources \& } \\
\text { community dev }\end{array}$ & 46 & $8.2 \%$ \\
\hline
\end{tabular}

\begin{tabular}{|l|c|c|}
\hline Position & Frequency & Percentage \\
\hline $\begin{array}{l}\text { C/D Roles } \\
\text { (Top management) }\end{array}$ & 3 & $0.5 \%$ \\
\hline $\begin{array}{l}\text { E/F Roles } \\
\text { (Middle management) }\end{array}$ & 27 & $4.8 \%$ \\
\hline $\begin{array}{l}\text { G Roles } \\
\text { (First line management) }\end{array}$ & 53 & $9.4 \%$ \\
\hline Rest & 479 & $85.2 \%$ \\
\hline
\end{tabular}

\begin{tabular}{|l|c|c|}
\hline Race & Frequency & Percentage \\
\hline White & 215 & $38.3 \%$ \\
\hline Black & 283 & $50.4 \%$ \\
\hline Coloured & 62 & $11.0 \%$ \\
\hline Rest & 2 & $0.4 \%$ \\
\hline Total & 562 & $100.0 \%$ \\
\hline
\end{tabular}

For the purpose of assessing the impact of the behaviour intervention on the safety statistics, the total mine was included in the analysis.

\subsection{Instruments}

The survey battery from a leading safety consultant group in the USA, trading as Safety Performance Solutions (SPS), was used to obtain the research information. The survey incorporates three separate scales (SPS, 2002), namely the Safety Perception Scale, the Safety Management System Scale and the Actively Caring Scale.

The Safety Perception Scale was used to assess employees' perceptions and opinions regarding how strongly they believe they and others within the organisation support safety. In addition, it addresses perceived management support for safety, peer support for safety and personal responsibility for safety. The number of survey questions that relate to these survey items, are 14, 15 and 6 respectively.

The Safety Management System Scale measures employee perceptions of formal safety management systems, including discipline, incident reporting and investigation, safety rules and procedures, safety training, safety communication, safety suggestions, rewards and reinforcement, and hazard identification and correction. In addition, it also asks for employees' opinions about the company's overall safety performance, the effects of stress, drugs and alcohol on safety, and the level of employee involvement in safety efforts. The number of survey questions that relate to these survey items are as follows: drugs and alcohol (3), discipline (5), incident reporting and investigation (9), rules and regulations (4), safety training (5), safety communication (5), safety suggestions (3), rewards and recognition (4), hazard identification (3), employee involvement (3), and general questions (5).

The Actively Caring Scale measures behaviour which directly or indirectly impacts on the safety of others. For each actively caring behaviour addressed in the survey (e.g. cautioning other employees when observing that they are involved in risky behaviour), three separate questions are asked. Respondents are asked whether they felt 
employees should perform the specific behaviour, whether they are willing to perform the behaviour (i.e. to caution his/her co-employee) and whether they do perform the behaviour (cautioning a coworker). Fifteen survey questions in total relate to this survey item.

The measuring battery was specifically designed for the organisation, with distinct demographic classifications within the organisation. Comparisons across different departments, different roles (gradings) and different race groups were possible because of the design. In the survey respondents were asked to respond to the survey items according to a five-point Likert scale varying from 1 (strongly disagree) to 5 (strongly agree) (SPS, 2002).

\subsection{Data analysis}

Overall responses for each scale were computed by taking the mean of all the questions making up that scale. The graphs depict the percentage of respondents who agree, disagree and neither agree nor disagree. Questionnaires were scanned by computer and the SPS software (SPS, 2002) was used to analyse responses. Since this research was longitudinal, the results of the first survey were compared with those of the second survey.

\subsection{Research procedure}

The measuring instruments were translated from English to Afrikaans and Setswana. The translation procedure was followed (Brislin, 1970). In terms of this procedure two independent translators translated the instrument from English to Afrikaans and Setswana, and then two other independent translators translated the product from Setswana and Afrikaans to English. The end product was then evaluated against the original questionnaire. A software program was developed to determine the names of those employees who were randomly selected to complete the questionnaire. A facilitator was nominated to facilitate a number of group sessions for those employees who were illiterate. Only one facilitator was deployed for this task, in order to avoid misinterpretation. The purpose of the research, the names of the nominees and the scheduling of the facilitation sessions were communicated to all employees. Employees completed the questionnaires and the facilitator followed up questionnaires that were not handed back to him. The questionnaires were then sent to the SPS offices in West Virginia, USA, where the data was analysed.

\subsection{Design of a practical model for implementing behaviour-based safety}

The mine went through a number of steps to implement the behaviour-based intervention. The first step was to evaluate the concept of behaviour-based safety. The mine selected an investigation team which included persons such as safety and health specialists at head office and two delegates from mine management. The second step was to achieve buy-in from both the executive team and, most importantly, from the different labour unions. The third step was to conduct a survey to assess the safety culture at the mine for the purpose of identifying those cultural aspects that needed attention to make the implementation successful. The fourth step was to develop a structure and to negotiate the implementation of the intervention with the labour unions. The next step was to implement training at three levels, namely management, the implementation team, and employees. Training for management emphasised the role of managers in supporting the programme. Training for the implementation team emphasised not only the roll-out planning that needed to be done, but also the practical implementation thereof. Training for employees was developed and presented by the implementation team. Once most of the employees in a section had been trained, a formal kick-off was arranged. After implementation a number of on-the-job training sessions were held in the workplace to coach people who still felt uncertain as to how they should go about completing an observation.

\section{4}

Results

Safety metrics fall into two basic areas, namely leading indicators (which are measurements linked to actions taken to prevent accidents), 
and trailing or lagging indicators, which are measurements linked to the outcome of an accident. Leading indicators are relevant to maximising safety performance by measuring, reporting and managing positive safe behaviour (Toellner, 2001). To achieve the ultimate goal of reducing accidents, safety resources must be focused on accident prevention processes rather than accident management processes. Examples of proactive actions focus on cultural issues, risk behaviour, participation and human error. Leading indicators are portrayed in Figure 1.

\section{Figure 1}

Leading and trailing indicators

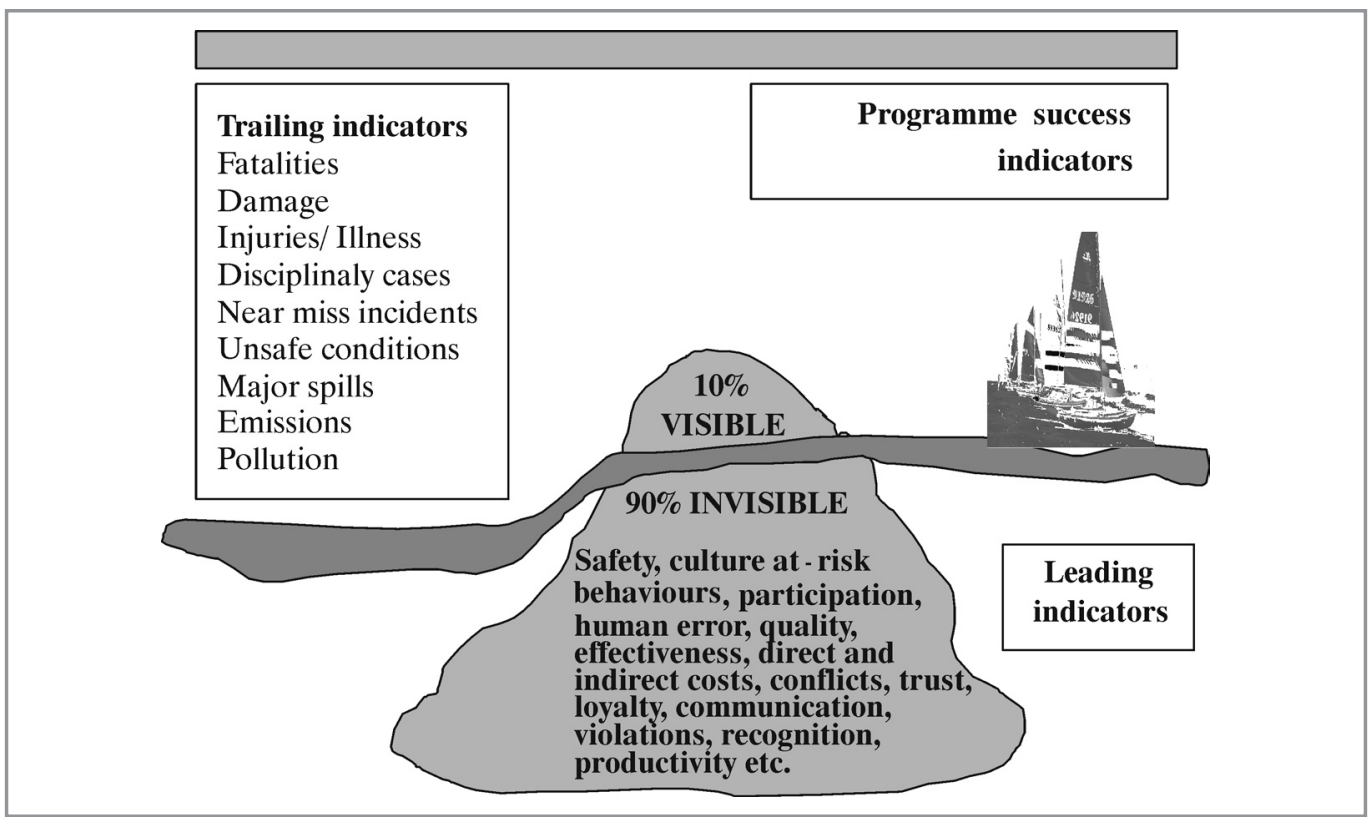

The most common trailing indicators (e.g., total recordable index, lost time index and number of days restricted or lost time) used by the American industry are those driven by the Occupational Safety and Health Association (OSHA) record-keeping requirements. As mentioned above, these are reactive indicators and executives erroneously continue to use incidence rate to measure performance.

Next, the results regarding the leading indicators are reported.

\section{Participation}

Since implementation of the programme at the mine the participation increased substantially (Figure 2).

The number of employee observations increased in a period of 12 months from 2426 (17 per cent) to 5354 (44 per cent) in March 2003. Not shown in the figure, is the percentage of risk behaviour. A high percentage of instances of risk behaviour was recorded by observers (between 30 per cent and 70 per cent) at the beginning of the 12 months period. In all the categories (except tools and equipment) the percentage of instances of risk behaviour decreased from between 50 per cent and 70 per cent to between 30 per cent and 50 per cent.

\section{Culture}

The Safety Perception Scale assesses employees' perceptions and opinions regarding how strongly they believe they and others within the organisation support safety. The score for management support for safety responses was 56 per cent favourable and 6 per cent higher in the 2001 survey than the 1999 survey (50 per cent). 40 per cent scored neutrally and 4 per cent unfavourably in the 2001 survey, as opposed to 47 per cent and 3 per cent respectively in the 1999 survey (Table 2 item 1). 
Figure 2

Total number of observations recorded

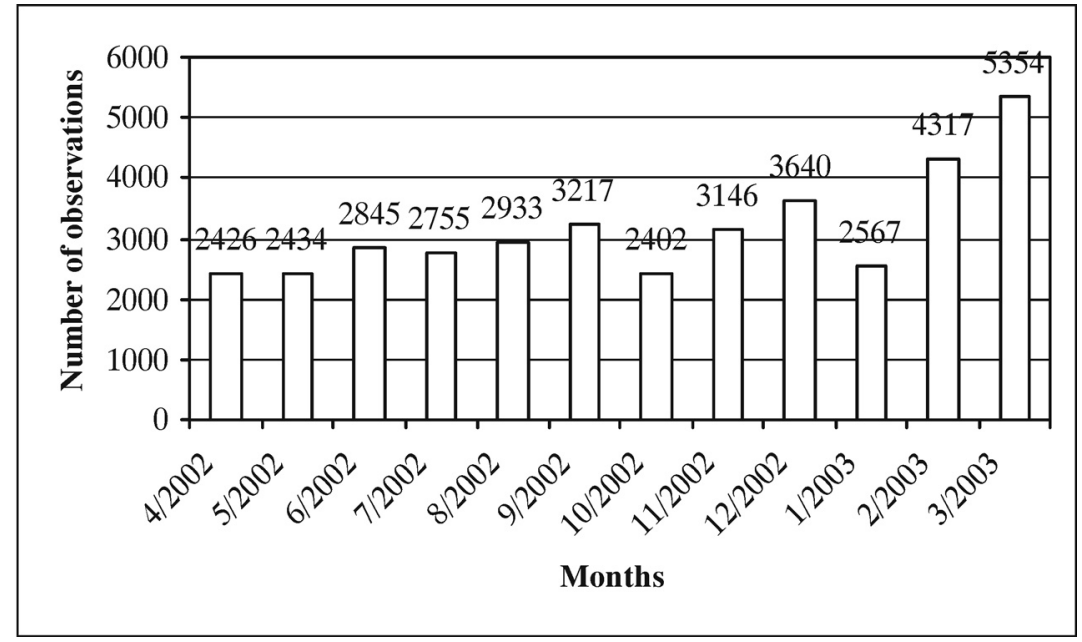

Table 2

Outcome of culture survey with regard to management support for safety

\begin{tabular}{|c|c|c|c|c|c|c|c|}
\hline \multirow[t]{2}{*}{ No } & \multirow[t]{2}{*}{ Item description } & \multicolumn{3}{|c|}{ December 1999} & \multicolumn{3}{|c|}{ October 2001} \\
\hline & & Favourable & Neutral & Unfavourable & Favourable & Neutral & Unfavourable \\
\hline 1.0 & $\begin{array}{l}\text { Overall management } \\
\text { support for safety }\end{array}$ & $50 \%$ & $47 \%$ & $3 \%$ & $56 \%$ & $40 \%$ & $4 \%$ \\
\hline 2.0 & $\begin{array}{l}\text { Management support per } \\
\text { department }\end{array}$ & & & & & & \\
\hline 2.1 & Plant maintenance & $46 \%$ & $46 \%$ & $8 \%$ & $68 \%$ & $28 \%$ & $4 \%$ \\
\hline 2.2 & Plant operations & $32 \%$ & $65 \%$ & $3 \%$ & $36 \%$ & $53 \%$ & $11 \%$ \\
\hline 2.3 & Mining maintenance & $64 \%$ & $35 \%$ & $1 \%$ & $58 \%$ & $40 \%$ & $2 \%$ \\
\hline 2.4 & Mining operations & $51 \%$ & $47 \%$ & $2 \%$ & $47 \%$ & $49 \%$ & $4 \%$ \\
\hline 2.5 & Engineering services & $33 \%$ & $60 \%$ & $7 \%$ & $68 \%$ & $28 \%$ & $4 \%$ \\
\hline 2.6 & Reconditioning section & $54 \%$ & $41 \%$ & $5 \%$ & $51 \%$ & $46 \%$ & $3 \%$ \\
\hline 2.7 & Staff functions & $66 \%$ & $34 \%$ & - & $76 \%$ & $22 \%$ & $2 \%$ \\
\hline 3.0 & $\begin{array}{l}\text { Management support per } \\
\text { position }\end{array}$ & & & & & & \\
\hline 3.1 & $\begin{array}{l}\mathrm{E}+\mathrm{F} \text { roles } \\
\text { (Middle management) }\end{array}$ & $78 \%$ & $22 \%$ & - & $68 \%$ & $32 \%$ & - \\
\hline 3.2 & $\begin{array}{l}\text { G roles } \\
\text { (First-line supervisors) }\end{array}$ & $70 \%$ & $25 \%$ & $5 \%$ & $79 \%$ & $17 \%$ & $4 \%$ \\
\hline 3.3 & Rest (Floor-level employees) & $46 \%$ & $51 \%$ & $3 \%$ & $51 \%$ & $44 \%$ & $5 \%$ \\
\hline 4.0 & $\begin{array}{l}\text { Management support per } \\
\text { race }\end{array}$ & & & & & & \\
\hline 4.1 & White employees & $63 \%$ & $33 \%$ & $4 \%$ & $68 \%$ & $29 \%$ & $3 \%$ \\
\hline 4.2 & Black employees & $38 \%$ & $60 \%$ & $2 \%$ & $43 \%$ & $51 \%$ & $6 \%$ \\
\hline 4.3 & Coloured employees & $61 \%$ & $39 \%$ & - & $67 \%$ & $27 \%$ & $6 \%$ \\
\hline
\end{tabular}


The demographic analysis revealed evidence of a significant positive shift in the Plant Maintenance, Engineering Services and Staff Functions (Items 2.1, 2.5 and 2.7). In the Pay Scale category, E and $\mathrm{F}$ roles (middle management and specialists) scored less favourably, while $\mathrm{G}$ roles (first-line management) and the rest of the employees scored more favourably in 2001 (Items 3.1-3.3). In the race category, all three races scored more favourably in 2001 (Items 4.1-4.3).

\section{Peer support}

The peer support for safety scale assesses employees' perceptions and opinions regarding how strongly they believe their peers (e.g. co-workers) support safety. Examples of this would be peers cautioning each about unsafe behaviour, peers appreciating feedback from their co-workers about safe behaviours, and employees feeling pressure from co-workers not to take short-cuts in safe working practices.

\section{Table 3}

Outcome of culture survey with regard to peer support for safety

\begin{tabular}{|c|c|c|c|c|c|c|c|}
\hline \multirow[t]{2}{*}{ No } & \multirow[t]{2}{*}{ Item description } & \multicolumn{3}{|c|}{ December 1999} & \multicolumn{3}{|c|}{ October 2001} \\
\hline & & Favourable & Neutral & Unfavourable & Favourable & Neutral & Unfavourable \\
\hline 1.0 & $\begin{array}{l}\text { Overall peer support for } \\
\text { safety }\end{array}$ & $50 \%$ & $49 \%$ & $1 \%$ & $63 \%$ & $34 \%$ & $3 \%$ \\
\hline 2.0 & $\begin{array}{l}\text { Peer support for safety per } \\
\text { department }\end{array}$ & & & & & & \\
\hline 2.1 & Plant maintenance & $50 \%$ & $48 \%$ & $2 \%$ & $66 \%$ & $28 \%$ & $6 \%$ \\
\hline 2.2 & Plant operations & $51 \%$ & $49 \%$ & - & $55 \%$ & $36 \%$ & $9 \%$ \\
\hline 2.3 & Mining maintenance & $42 \%$ & $58 \%$ & - & $58 \%$ & $40 \%$ & $2 \%$ \\
\hline 2.4 & Mining operations & $56 \%$ & $42 \%$ & $2 \%$ & $63 \%$ & $34 \%$ & $3 \%$ \\
\hline 2.5 & Engineering services & $30 \%$ & $68 \%$ & $2 \%$ & $70 \%$ & $28 \%$ & $2 \%$ \\
\hline 2.6 & Reconditioning section & $49 \%$ & $49 \%$ & $2 \%$ & $44 \%$ & $54 \%$ & $2 \%$ \\
\hline 2.7 & Staff functions & $56 \%$ & $43 \%$ & $1 \%$ & $74 \%$ & $24 \%$ & $2 \%$ \\
\hline 3.0 & Peer support per position & & & & & & \\
\hline 3.1 & $\begin{array}{l}\mathrm{E}+\mathrm{F} \text { roles } \\
\text { (middle management) }\end{array}$ & $41 \%$ & $59 \%$ & - & $60 \%$ & $40 \%$ & - \\
\hline 3.2 & G roles (first-line supervisors) & $51 \%$ & $43 \%$ & $6 \%$ & $73 \%$ & $24 \%$ & $3 \%$ \\
\hline 3.3 & Rest (floor-level employees) & $50 \%$ & $49 \%$ & $1 \%$ & $61 \%$ & $35 \%$ & $4 \%$ \\
\hline 4.0 & Peer support per race & & & & & & \\
\hline 4.1 & White employees & $46 \%$ & $52 \%$ & $2 \%$ & $63 \%$ & $34 \%$ & $3 \%$ \\
\hline 4.2 & Black employees & $53 \%$ & $47 \%$ & - & $61 \%$ & $34 \%$ & $5 \%$ \\
\hline 4.3 & Coloured employees & $52 \%$ & $48 \%$ & - & $61 \%$ & $33 \%$ & $6 \%$ \\
\hline
\end{tabular}

Scores of the 2001 survey were higher than those of the 1999 survey (63 per cent versus 50 per cent favourable, 34 per cent versus 49 per cent neutral, and 3 per cent versus 1 per cent unfavourable) (Item 1). All departments (except for Reconditioning) scored higher in 2001, with several departments scoring significantly higher (Items 2.1-2.7). In the Pay Scale category, all groups scored much higher in 2001 (Items 3.1-3.3). In the Race category, all groups scored significantly higher in 2001 (Items 4.1-4.3).

\section{Personal responsibility for safety}

The Personal Responsibility for Safety scale assesses employees' perceptions and opinions regarding how strongly they believe they 
support safety. Responses from the 2001 survey scored higher than the 1999 survey (86 per cent favourable, versus 79 per cent) (Table 4 item $1.0)$.

Table 4

Outcome of culture survey with regard to perceptions of personal responsibility for safety

\begin{tabular}{|c|c|c|c|c|c|c|c|}
\hline \multirow[t]{2}{*}{ No } & \multirow[t]{2}{*}{ Item description } & \multicolumn{3}{|c|}{ December 1999} & \multicolumn{3}{|c|}{ October 2001} \\
\hline & & Favourable & Neutral & Unfavourable & Favourable & Neutral & Unfavourable \\
\hline 1.0 & $\begin{array}{l}\text { Overall personal responsibility } \\
\text { for safety }\end{array}$ & $79 \%$ & $18 \%$ & $3 \%$ & $86 \%$ & $11 \%$ & $3 \%$ \\
\hline 2.0 & $\begin{array}{l}\text { Personal responsibility for } \\
\text { safety per department }\end{array}$ & & & & & & \\
\hline 2.1 & Plant maintenance & $77 \%$ & $18 \%$ & $5 \%$ & $85 \%$ & $11 \%$ & $4 \%$ \\
\hline 2.2 & Plant operations & $70 \%$ & $26 \%$ & $4 \%$ & $84 \%$ & $9 \%$ & $7 \%$ \\
\hline 2.3 & Mining maintenance & $77 \%$ & $23 \%$ & - & $88 \%$ & $10 \%$ & $2 \%$ \\
\hline 2.4 & Mining operations & $84 \%$ & $15 \%$ & $1 \%$ & $84 \%$ & $12 \%$ & $4 \%$ \\
\hline 2.5 & Engineering services & $68 \%$ & $25 \%$ & $7 \%$ & $95 \%$ & $5 \%$ & - \\
\hline 2.6 & Reconditioning section & $69 \%$ & $31 \%$ & - & $68 \%$ & $32 \%$ & - \\
\hline 2.7 & Staff functions & $94 \%$ & $5 \%$ & $1 \%$ & $94 \%$ & $4 \%$ & $2 \%$ \\
\hline 3.0 & $\begin{array}{l}\text { Personal responsibility for } \\
\text { safety per position }\end{array}$ & & & & & & \\
\hline 3.1 & $\begin{array}{l}\mathrm{E}+\mathrm{F} \text { roles } \\
\text { (middle management) }\end{array}$ & $93 \%$ & $7 \%$ & - & $100 \%$ & - & - \\
\hline 3.2 & $\mathrm{G}$ roles (first-line supervisors) & $83 \%$ & $9 \%$ & $8 \%$ & $94 \%$ & $3 \%$ & $3 \%$ \\
\hline 3.3 & Rest (floor-level employees) & $78 \%$ & $20 \%$ & $2 \%$ & $83 \%$ & $13 \%$ & $4 \%$ \\
\hline 4.0 & $\begin{array}{l}\text { Personal responsibility for } \\
\text { safety per race }\end{array}$ & & & & & & \\
\hline 4.1 & White employees & $84 \%$ & $13 \%$ & $3 \%$ & $90 \%$ & $9 \%$ & $1 \%$ \\
\hline 4.2 & Black employees & $77 \%$ & $21 \%$ & $2 \%$ & $82 \%$ & $13 \%$ & $5 \%$ \\
\hline 4.3 & Coloured employees & $76 \%$ & $24 \%$ & - & $85 \%$ & $9 \%$ & $6 \%$ \\
\hline
\end{tabular}

Four groups improved from the 1999 results, two groups scored the same and one group scored slightly lower (Items 2.12.7). In the Pay Scale category, all groups improved from 1999 (Items 3.1-3.3). In the Race category, the score of all three races improved (Items 4.1-4.3). Four groups improved from the 1999 results, two groups scored the same and one group scored slightly lower. In the Pay Scale category, all groups improved from 1999. In the Race category, all three races improved.

\section{Safety management systems}

The safety management system scale measures employee perception of a variety of formal management systems, including discipline, incident reporting and investigation, safety rules and procedures, safety training, safety communication, safety suggestions, rewards and reinforcement, and hazard identification and correction. In addition, it also assesses employees' opinions of the company's safety performance, the effects of stress, drugs and alcohol on safety, and the level of employee involvement in safety. 
Table 5

Outcomes of culture survey regarding perceptions of management systems

\begin{tabular}{|c|c|c|c|c|c|c|c|}
\hline No & Item & \multicolumn{3}{|c|}{ December 1999} & \multicolumn{3}{|c|}{ October 2001} \\
\hline & & Favourable & Neutral & Unfavourable & Favourable & Neutral & Unfavourable \\
\hline 1 & $\begin{array}{l}\text { Overall perception of } \\
\text { management systems }\end{array}$ & $64 \%$ & $20 \%$ & $16 \%$ & $70 \%$ & $14 \%$ & $16 \%$ \\
\hline 2 & $\begin{array}{l}\text { Perception that drugs or alcohol } \\
\text { is not a problem in the mine }\end{array}$ & $58 \%$ & $14 \%$ & $28 \%$ & $65 \%$ & $13 \%$ & $16 \%$ \\
\hline 3 & $\begin{array}{l}\text { Perception that employees will } \\
\text { not be disciplined for having a } \\
\text { work injury }\end{array}$ & $55 \%$ & $27 \%$ & $18 \%$ & $74 \%$ & $26 \%$ & - \\
\hline 4 & $\begin{array}{l}\text { Perception that minor injuries } \\
\text { are not being reported }\end{array}$ & $46 \%$ & $22 \%$ & $32 \%$ & $56 \%$ & $16 \%$ & $28 \%$ \\
\hline 5 & $\begin{array}{l}\text { Perception that injuries are } \\
\text { thoroughly investigated }\end{array}$ & $73 \%$ & $13 \%$ & $14 \%$ & $75 \%$ & $13 \%$ & $12 \%$ \\
\hline 6 & $\begin{array}{l}\text { Employees understand the } \\
\text { reasons behind safety rules }\end{array}$ & $73 \%$ & $28 \%$ & $19 \%$ & $76 \%$ & $13 \%$ & $11 \%$ \\
\hline 7 & $\begin{array}{l}\text { Employees understand the } \\
\text { potential of hazards in their jobs }\end{array}$ & $73 \%$ & $15 \%$ & $12 \%$ & $79 \%$ & $11 \%$ & $10 \%$ \\
\hline 8 & $\begin{array}{l}\text { Perception of good } \\
\text { communication about safety }\end{array}$ & $64 \%$ & $18 \%$ & $18 \%$ & $66 \%$ & $15 \%$ & $19 \%$ \\
\hline 9 & $\begin{array}{l}\text { Employees received adequate } \\
\text { training for their jobs }\end{array}$ & $68 \%$ & $15 \%$ & $17 \%$ & $77 \%$ & $10 \%$ & $13 \%$ \\
\hline 10 & $\begin{array}{l}\text { Employees received feedback } \\
\text { from supervisors if they were } \\
\text { observed working unsafely }\end{array}$ & $58 \%$ & $21 \%$ & $21 \%$ & $71 \%$ & $14 \%$ & $15 \%$ \\
\hline 11 & $\begin{array}{l}\text { Employee safety suggestions are } \\
\text { taken seriously }\end{array}$ & $64 \%$ & $17 \%$ & $19 \%$ & $69 \%$ & $16 \%$ & $15 \%$ \\
\hline 12 & $\begin{array}{l}\text { Supervisors acknowledge safe } \\
\text { behaviour by employees }\end{array}$ & $52 \%$ & $21 \%$ & $27 \%$ & $54 \%$ & $21 \%$ & $25 \%$ \\
\hline 13 & $\begin{array}{l}\text { Employees are motivated by the } \\
\text { safety reward programme }\end{array}$ & $67 \%$ & $14 \%$ & $19 \%$ & $73 \%$ & $11 \%$ & $16 \%$ \\
\hline 14 & $\begin{array}{l}\text { Employees are encouraged to } \\
\text { participate in defining safe work } \\
\text { practices }\end{array}$ & $73 \%$ & $16 \%$ & $11 \%$ & $76 \%$ & $11 \%$ & $13 \%$ \\
\hline 15 & $\begin{array}{l}\text { Safety meetings help make the } \\
\text { mine a safer place }\end{array}$ & $74 \%$ & $13 \%$ & $13 \%$ & $76 \%$ & $10 \%$ & $14 \%$ \\
\hline
\end{tabular}

Although there was a 7 per cent improvement from 1999 to 2001, 16 per cent of responses still indicate alcohol or drug abuse is a problem in the workplace (Item 2). As far as discipline (Item 3 ) is concerned, the result improved from 55 per cent in 1999 to 74 per cent in 2001, but many employees still believe that it is common for employees to be disciplined for having an injury. Almost one third of respondents felt that they had been disciplined for having an injury, and that discipline was not used often enough for serious safety violations. 
Responses concerning incident reporting and investigation in 2001 (75 per cent favourable) were only slightly better than in 1999 (73 per cent favourable responses). Different groups showed different patterns, though, and mine maintenance for instance increased their favourable ratings by 22 per cent, while mining operations decreased their favourable ratings by 10 per cent. Concerning rules and regulations, the results show a 76 per cent favourable response in 2001 against the 73 per cent in 1999. This represents a 3 per cent positive shift. 11 per cent responded unfavourably in 2001, as opposed to 19 per cent in 1999.

On the question of receiving adequate safety training, 77 per cent responded favourably in 2001, as opposed to 68 per cent in 1999. With regard to receiving feedback about observed unsafe work, the responses in 2001 were 71 per cent favourable as opposed to 58 per cent favourable in 1999. This represents a 13 per cent improvement. The 2001 scores concerning safety suggestions improved slightly compared to 1999 (from 64 per cent favourable in 1999 to 69 per cent favourable in 2001). Most groups believed their safety suggestions were taken more seriously in 2001 than in 1999.

Favourable responses regarding rewards and reinforcement increased from 67 per cent in 1999 to 73 per cent in 2001, and unfavourable responses decreased from 19 per cent in 1999 to 16 per cent in 2001. Favourable responses regarding hazard identification and correction increased from 73 per cent in 1999 to 76 per cent in 2001. Unfavourable responses increased from 11 per cent in 1999 to 13 per cent in 2001.

\section{Active caring}

The Actively Caring Scale measures individuals' intentions and attitudes toward demonstrating actively caring behaviour toward fellow employees. Respondents were asked if they were willing to perform actively caring behaviour, and if they currently performed the actively caring deeds. Overall, the 2001 results showed slight improvements over the 1999 results.

Table 6

Outcome of culture survey with regard to the perception of actively caring

\begin{tabular}{|c|c|c|c|c|c|c|c|}
\hline \multirow[t]{2}{*}{ No } & \multirow[t]{2}{*}{ Item description } & \multicolumn{3}{|c|}{ December 1999} & \multicolumn{3}{|c|}{ October 2001} \\
\hline & & Favourable & Neutral & Unfavourable & Favourable & Neutral & Unfavourable \\
\hline 1. & $\begin{array}{l}\text { Overall perception of actively } \\
\text { caring for safety }\end{array}$ & $79 \%$ & $11 \%$ & $10 \%$ & $82 \%$ & $8 \%$ & $10 \%$ \\
\hline 2. & $\begin{array}{l}\text { Employees should actively care } \\
\text { for one another }\end{array}$ & $85 \%$ & $7 \%$ & $8 \%$ & $85 \%$ & $7 \%$ & $8 \%$ \\
\hline 3. & $\begin{array}{l}\text { Employees are willing to actively } \\
\text { care for one another }\end{array}$ & $83 \%$ & $9 \%$ & $8 \%$ & $85 \%$ & $6 \%$ & $9 \%$ \\
\hline 4. & $\begin{array}{l}\text { Employees do actively care for } \\
\text { one another }\end{array}$ & $79 \%$ & $10 \%$ & $11 \%$ & $82 \%$ & $8 \%$ & $10 \%$ \\
\hline 5. & $\begin{array}{l}\text { Employees should praise others } \\
\text { for working safely }\end{array}$ & $88 \%$ & $6 \%$ & $6 \%$ & $88 \%$ & $6 \%$ & $6 \%$ \\
\hline 6. & $\begin{array}{l}\text { Employees are willing to praise } \\
\text { others for working safely }\end{array}$ & $85 \%$ & $7 \%$ & $8 \%$ & $88 \%$ & $5 \%$ & $7 \%$ \\
\hline 7. & $\begin{array}{l}\text { Employees do praise others for } \\
\text { working safely }\end{array}$ & $80 \%$ & $9 \%$ & $11 \%$ & $81 \%$ & $7 \%$ & $12 \%$ \\
\hline 8. & $\begin{array}{l}\text { Employees should caution co- } \\
\text { workers for working unsafely }\end{array}$ & $88 \%$ & $4 \%$ & $8 \%$ & $87 \%$ & $5 \%$ & $8 \%$ \\
\hline 9. & $\begin{array}{l}\text { Employees are willing to caution } \\
\text { co-workers for working unsafely }\end{array}$ & $82 \%$ & $8 \%$ & $10 \%$ & $83 \%$ & $6 \%$ & $11 \%$ \\
\hline 10. & $\begin{array}{l}\text { Employees do caution co- } \\
\text { workers for working unsafely }\end{array}$ & $88 \%$ & $6 \%$ & $6 \%$ & $87 \%$ & $6 \%$ & $7 \%$ \\
\hline
\end{tabular}


All groups showed improvements from 1999, with Engineering Services showing the greatest increases. In particular, responses were very high on the "Praise" items. In terms of all the questions asked, increases of 5 per cent for the "Should" items, 7 per cent for the "Willing" items, and 16 per cent for the "Do" items were recorded.

In terms of trailing indicators, the most common indicator that is used in the industry is that of the lost time injury frequency rate. The performance of the mine is portrayed in
Figure 3. The lost time injury frequency rate is calculated as the number of lost-time injuries per million hours worked.

For the year prior to the implementation of the behaviour-based safety intervention (1999), the mine recorded a lost-time injury frequency rate of 5.53 (per million hours worked). For the year in which implementation commenced, the frequency rate dropped to 4.23 , and to 4.33 and 4.32 respectively for the subsequent years (see Figure 3).

Figure 3

Trend for lost-time injury frequency rate

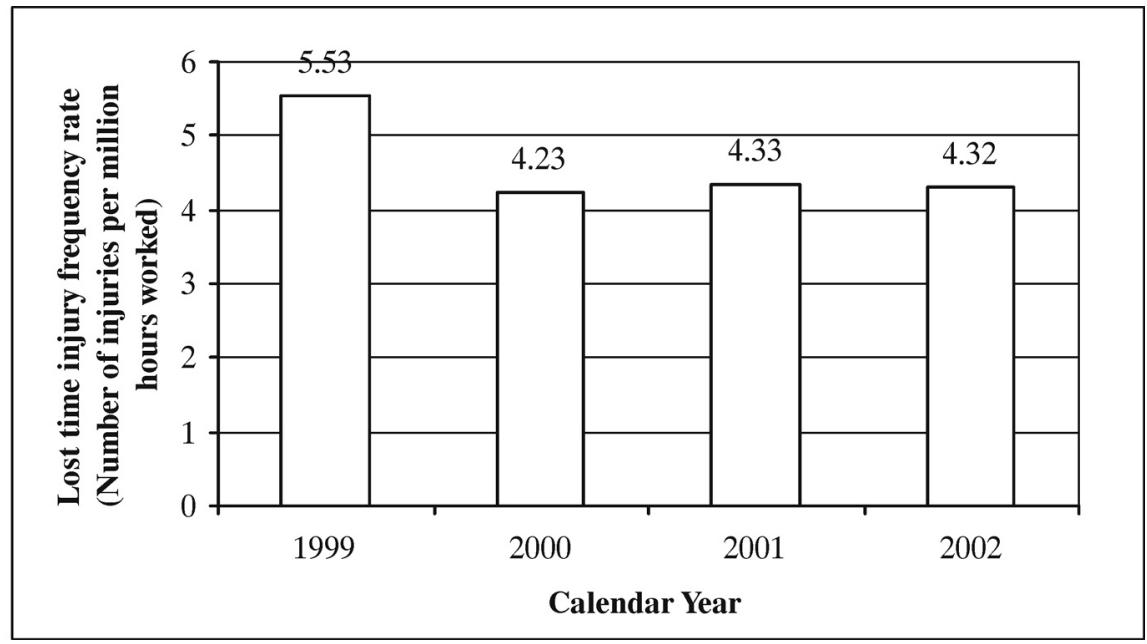

\section{5}

\section{Discussion}

The aim of this study was to determine to what extent the safety culture and safety performance in an iron ore mine were affected by the implementation of a behaviour-based safety intervention. The results showed that the implementation of a behaviour-based intervention contributed to the improvement of the safety culture in the mine.

The increase in participation in the behaviourbased safety programme is encouraging because participation was voluntary and no pressure was exerted by management, nor were any management objectives set. The conclusion is that employees' buy-in was achieved for the programme and that the employees became aware of the advantages of the programme.
During the programme, management emphasised recognition for participation. The decrease in the percentage of instances of risk behaviour and the increase in the percentage of instances of safe behaviour were exactly what the programme was aiming at. Because risk behaviour was targeted and measured in the programme, employees were very much aware of the emphasis on this behaviour, which ultimately led to the decrease in risk behaviour.

The details of each question indicate that employees perceived management as being less concerned with keeping injury statistics low and more concerned with keeping people safe. Compared to 1999 data, managers were seen as more sincere about reducing injuries in 2001, and more willing to invest money and effort to improve safety. However, it is disappointing that more employees felt that 
managers were likely to place production over safety. Supervisors were viewed less favourably than managers. More employees believed that supervisors were more likely to place production above safety, and to force employees to perform unsafe tasks. Furthermore, fewer employees perceived supervisors as encouraging employees to overlook hazards than in 1999.

There were significant gains from 1999 in two areas, namely giving and receiving feedback, and taking shortcuts. In all the specific questions regarding these two issues, the 2001 perception was much more favourable than responses in 1999. In addition, employees responded much more favourably when asked if feedback on safe behaviour was appreciated. Unfortunately, employees were less appreciative about receiving feedback on unsafe behaviour. Employees reported they performed fewer shortcuts and felt less pressure from co-workers to perform these shortcuts.

Regarding personal responsibility for safety, two aspects are worth discussing. Firstly, most groups reported that they had more respect for employees who try to work safely than for those who do not. Secondly, fewer employees reported overlooking safety hazards to complete the job than during 1999. When asked whether employees tried to follow safety rules, the overall scores were similar to the 1999 scores. In a related item, employees were asked if they sometimes overlooked hazards to complete the job. The overall response to this was more favourable in 2001.

The overall perception regarding management systems was 70 per cent favourable in October 2001, compared to the 64 per cent in December 1999. Although this is encouraging, there is a real concern regarding some of the items that were measured. Although there was a 7 per cent improvement from 1999 to 2001, it is a concern that 16 per cent of responses still indicate alcohol or drug abuse as a problem in the workplace. Management has introduced a number of programmes to counter this problem, because the safety risk caused by drugs and alcohol is a serious concern.

The improvement from 55 per cent (1999) to 74 per cent (2001) in discipline is impressive, but many employees still believed that it is common for employees to be disciplined for having an injury. The improvement is mainly due to a new approach towards conducting investigations, which involves not concentrating on identifying a guilty party, but rather on identifying the root cause of the problem. Furthermore, in spite of having been encouraged to report near misses, many groups showed a decrease in the belief that near misses are consistently reported and investigated. Although 75 per cent of the 2001 respondents admitted they would report a minor injury if they sustained one, only 56 per cent of 2001 respondents reported they felt minor injuries were not being reported. The response for this item was 46 per cent in 1999, and the increase of 12 per cent is therefore a real concern.

The 2001 responses regarding rules and regulations were more favourable than the 1999 scores. Even though 76 per cent of 2001 respondents feel that employees understand the reasons behind the company's safety rules, 40 per cent believe the site has too many safety rules.

Regarding training, the 2001 scores were more favourable than the 1999 scores. The biggest improvement concerned the perception that employees have received adequate safety training. This is mainly because of the emphasis on safety training during the implementation of the behaviour-based safety intervention. Concerning communication, the 2001 scores were higher than the 1999 scores. The biggest improvement (13 per cent) was in the area of supervisor feedback, especially if employees were seen working unsafely. There was an increase from 73 per cent to 76 per cent with regard to employees believing that they were being encouraged to participate in defining safe working procedures. It may be concluded that these responses are the results of implementing a behaviour-based safety programme by means of which people are encouraged to give feedback in a structured way. As far as safety suggestions are concerned, the 5 per cent increase in favourable responses from 1999 to 2001 is mainly due to the structured way in which safety suggestions are recorded and investigated, and feedback is given in the behaviour-based safety process.

As regards rewards and reinforcement, the scores in 2001 were higher than in 1999, 
although there were significant differences among the different groups. A majority of employees felt the company's safety award programme motivated them to work more safely. There was a tremendous amount of disagreement surrounding the issue of how injuries affect promotions and performance evaluations. Several groups believed that sustaining an injury would reduce an employee's chance of promotion and would result in a poorer performance assessment, while other groups did not.

Overall, the organisation scored slightly higher as far as hazard identification and correction were concerned in 2001 compared with 1999. Differences were recorded on the issue of how often audits were conducted and whether the hazards found during the inspection were corrected quickly. The fact that employees understood the potential of hazards in their jobs better in 2001 was encouraging. Perceptions about the usefulness of the safety committee's efforts had improved considerably from 1999 (76 per cent positive). Secondly, the 2001 scores were still much lower (39 per cent) than would be expected in terms of whether the site spent too much effort on safety.

The results indicate that employees look for and take advantage of opportunities to give each other positive feedback for safe behaviour. It also indicates that employees recognise and receive feedback, and look for hazards within their work environment. Employees at the mine are thus caring for one another. Although the decrease in the injury frequency represents a significant improvement of 20 per cent, there is still room for improvement.

The implementation of the behaviour-based safety intervention seems to have contributed to a new safety culture at the mine. The strongest impact is experienced in the areas of management support for safety, active caring among co-workers, and a number of safety systems. The intervention also favourably impacted on the lost-time injury frequency. Although it was expected that such a shift in the culture would have a more significant impact on the safety statistics, it should be remembered that the outcome of an accident is coincidental (whether the injury is minor or major). Therefore it is difficult to draw conclusions from safety statistics. It is also encouraging that participation in the programme is still increasing. However, one would like to see participation increase from the current 44 per cent per month to at least near 100 per cent per month.

These results suggest that it is possible to make an impact with a behaviour-based intervention in developing countries, such as Africa, with its unique cultures and restricting factors like illiteracy, racial issues and diversity. Similar results were achieved in first-world countries like Australia and America, although the environment in those countries is quite different from that of South Africa, especially in the mining industry. What must be realised is that to make a behavioural approach work in Africa, the approach needs to be more intense in order to deal with issues like labour union participation, illiteracy, politics and diversity.

The conclusion that behaviour-based safety is an effective tool to address the behaviour dimension of safety should not be interpreted as if it is suggested that behaviour safety will solve all the safety problems at a particular site. On the contrary, as was mentioned in the introduction, it is essential to devote equal attention to all three the dimensions of safety, namely the environment, the person, and behaviour.

\section{6}

\section{Recommendations}

Because human behaviour is a contributing cause to most incidents and injuries, safety excellence can only be achieved by addressing the human dimensions of safety. It is recommended that industrial companies shift their focus from traditional safety approaches to also include a strong focus on the human dimensions of safety. This does not imply ignoring the environment and person factors. Such an approach would be fatal because the three domains of safety are interrelated. Instead, it implies a drive to include behaviour as an integral part of the safety system.

Secondly, the research proved that behaviourbased safety could in fact be a very useful tool as an intervention to address the behaviour dimension and to influence the safety culture. 
Thus, it is recommended that the behaviourbased safety model should be applied by companies. It can be administered by individuals with minimal professional training and can reach people in all settings where unsafe conditions occur.

It is clear that a behaviour-based intervention cannot just be bought "off the shelf" in a developed country and implemented in a developing third world country. It is necessary to adapt the programme to fit the local circumstances. Therefore, companies which consider the behaviour-based safety tool should make the necessary adaptations to fit it to their particular circumstances.

\section{References}

1 BIRD, E.E. \& GERMAIN, G.L. (1996) Practical Loss Control Leadership, International Loss Control Institute: Georgia, USA.

2 BLAIR, E. (1999) "Behavior-based safety: Myths, magic, reality”, Professional Safety, 44(88): 25-29.

3 BRISLIN, R.W. (1970) "Back translation for cross-cultural research", Journal of Cross-cultural Research, 1: 185-126.

4 DEPARTMENT OF LABOUR (2002) "Preliminary Annual Report: 2001/2002", Accessed Nov 2002 from http://stats.bls.gov.

5 FINDLEY, B. (2003) "Behaviour-based safety", Accessed April 2003, from www.stevenspublishing. com.

6 GELLER, E.S. (1996) Working Safe, CRC Press: Boca Raton.

7 GELLER, E.S. (1998) Safety Accountability and Beyond: How to Increase People's Responsibility for Safety and Health, WI: J.J. Keller \& Associates Inc: Neenah.

8 GELLER, E.S.; BOYCE, T.E.; WILLIAMS, J.H.; PETTINGER, B.; DE PASQUALE, P. \& CLARKE, S. (1998) "Researching behaviour based safety: A multi-method assessment and evaluation.” Paper presented at the 37th Annual Professional Development Conference and Exposition, Des Plaines, IL. American Society of Safety Engineers.

9 GUASTELLO, S.J. (1993) "Do we really know how well our occupational accident prevention programs work?", Safety Science, 16: 445-463.

10 GUN CONTROL ALLIANCE. (2002) "Gun free South Africa: sheet, facts and figures", Accessed September 2002 from www.gca.org.za.
11 HUYSAMEN, G.K. (1996) Metodologie vir die Sosiale en Gedragswetenskappe, International Thompson Publishing: Cape Town.

12 INTERNATIONAL LABOUR ORGANISATION. (1999) "Introductory report of the International Labor Office", Accessed November 2002, from www.ilo.org.

13 KRAUSE, T.R. (1995) Employee Driven Systems for Safe Behavior, Van Nostrand Reinold: New York.

14 KRAUSE, T.R. (2001) "Moving to the second generation in behavior-based safety", Professional Safety, 46(5): 27-32.

15 LEEDY, P.D. (2001) Practical Research: Planning and Design, Macmillan: New York.

16 SANDERS, M.S. \& MCCORMICK, E.J. (1993)

Human Factors in Engineering and Design, McGraw-Hill: New York.

17 SKINNER, B.F. (1965) Science and Human Behaviour, The Free Press: New York.

18 SMITH, M.J.; KARSH, B.; CARAYON, P. \& CONWAY, T. (2003) "Controlling occupational safety and health hazards”, In J.C. Quick \& L. E. Tetrick (eds.) Handbook of Occupational Health Psychology Washington: American Psychological Association: 35-68.

19 SPS (2002) "Safety culture assessment", Accessed November 2002 from www.safetyperformance. com.

20 TOELLNER, J. (2001) "Improving safety and health performance: identifying and measuring leading indicators", Professional Safety, 46(9): 42-47. 